\title{
A COLONIALIDADE DO GÊNERO E PODER: DA PÓS- COLONIALIDADE À DECOLONIALIDADE ${ }^{1}$
}

\author{
Coloniality of Gender and Power: From Postcoloniality to Decoloniality
}

\author{
Breny MENDOZA \\ Universidade Estatal de California, Northridge \\ breny.mendoza@csun.edu \\ Tradução de Letícia Pilger DA SILVA \\ Universidade Federal do Paraná \\ leticiaspilger@gmail.com \\ https://orcid.org/0000-0002-1999-7336 \\ Sueliton de Oliveira SILVA FILHO \\ Universidade Federal do Paraná \\ seul.literato92@gmail.com \\ https://orcid.org/0000-0001-7740-794X
}

\begin{abstract}
RESUMO: Teorias anticoloniais analisam complexas relações de poder entre o colonizador e o colonizado para promover projetos políticos de descolonização. Este artigo situa as teorias feministas anticoloniais em relação a duas linhas de pensamento anticolonial, as teorias pós-colonial e decolonial, particularmente a vertente da teoria decolonial desenvolvida pelos pensadores do grupo Modernidade/Colonialidade da América Latina. Compara-se os conceitos centrais dos argumentos teóricos e projetos políticos associados a interseccionalidade, feminismo pós-colonial, e o feminismo decolonial que Maria Lugones aprofundou com sua noção de colonialidade de gênero. $\mathrm{O}$ artigo explora a recepção do trabalho de Lugones na América Latina e as análises que a teoria decolonial oferece para a criação de projetos contemporâneos de justiça social. PALAVRAS-CHAVE: colonialidade de gênero; colonialidade de poder; feminismo decolonial; interseccionalidade, opção decolonial; feminismo pós-colonial.
\end{abstract}

ABSTRACT: Anticolonial theories analyze complex power relations between the colonizer and the colonized to promote the political project of decolonization. This chapter situates anticolonial feminist theories in relation to two schools of anticolonial thinking,

1 Publicação original: MENDOZA, Breny. "La colonialidad del género y poder: de la postcolonialidad a la decolonialidad". In: MUÑOZ, Karina Ochoa (Org.). Miradas en torno al problema colonial. Cidade do México: Ediciones Akal, 2019, p. 35-72. 
postcolonial and decolonial theory, particularly the strand of decolonial theory developed by the modernity/coloniality school of thought of Latin America. It compares key theoretical arguments and political projects associated with intersectionality, postcolonial feminism, and the decolonial feminism that Maria Lugones has advanced with her notion of the coloniality of gender. The chapter explores the reception of Lugones work in Latin America and the critical insights that decolonial theory offers contemporary social justice projects. KEYWORDS: coloniality of gender; coloniality of power; decolonial feminism intersectionality, decolonial option; postcolonial feminism.

\section{ANTECEDENTES}

O mundo acadêmico anglo-saxão costuma associar as lutas anticoloniais aos movimentos de liberação nacional que lutaram pela sua "independência" em relação aos poderes coloniais europeus, ou aos movimentos sociais que surgem no processo de constituição do Estado-nação, uma vez que os poderes coloniais foram expulsos. As teorias anticoloniais estão relacionadas a figuras como o pensador pan-afro-americano W. E. B. DuBois, nascido nos Estados Unidos, e os reconhecidos críticos do colonialismo francês, como Aimé Césaire e Frantz Fanon, assim como o líder da independência de Gana, Kwame Nkrumah. Em 1978, no entanto, o cânone das teorias anticoloniais se expandiu com a publicação do magistral livro Orientalismo, de Edward Said, um teórico de literatura palestino-americano que não só ampliou o marco histórico, a cartografia e o valor epistêmico do colonialismo, mas também redefiniu edeslocou o campo do conhecimento do anticolonial em direção a um novo marco teórico que conhecemos hoje como a teoria pós-colonial. Mais adiante, nos anos noventa, o Grupo de Estudos Subalternos do Sudeste Asiático nos introduziu a uma nova geração de teóricos do póscolonial, com autores como Ranajit Guha, Homi Bhabba, Partha Chaatterjee, Dipesh Chakravorty e Gayatri Chakravorty Spivak.

Em comparação com os teóricos pós-coloniais que situam suas análises nas práticas coloniais do norte europeu, teóricos latino-americanos e caribenhos nos lembram que o pensamento anticolonial surge em um contexto colonial muito mais antigo, como resposta à história violenta do colonialismo europeu que se inaugura na Espanha em 1492. O giro decolonial do mundo acadêmico atual é liderado por pesquisadores latino-americanos e caribenhos associados ao denominado Grupo de Modernidade/Colonialidade, o qual tem construído um arquivo de textos que abarca desde o século XVI até o momento presente, 
oferecendo uma reinterpretação radical do capitalismo. ${ }^{2}$ Em seu momento de auge, o grupo de pensamento da Modernidade/Colonialidade argumenta que a Modernidade e o capitalismo não são resultados de processos históricos intereuropeus, mas a consequência lógica do processo histórico do colonialismo. Alguns dos teóricos dessa corrente são o sociólogo peruano Aníbal Quijano, que teoriza o conceito central da teoria decolonial: a colonialidade do poder; os argentinos Enrique Dussel, conhecido por sua filosofia de libertação e o conceito de transmodernidade, Walter Mignolo, semiótico, autor de El lado más oscuro del Renacimiento (1995, 2009), e Nelson Maldonado-Torres, filósofo portoriquenho que desenvolve o conceito da colonialidade do ser, entre outros.

\section{SURGIMENTO E APROFUNDAMENTO}

A teoria feminista anticolonial surgiu neste rico contexto; entretanto, ocupa uma posição marginal tanto no interior das críticas ao colonialismo quanto na teoria feminista ocidental. A brilhante obra de Gayatri Chakravorty Spivak é um bom exemplo de como esta complexa marginalização é produzida. Mais de um teórico pós-colonial levantou o questionamento acerca da inserção de sua obra dentro do Grupo de Estudos Subalternos do Sudeste Asiático. Vivek Chibber afirmou (2013, p. 8) que Spivak havia caído de paraquedas nos debates do Grupo de Estudos Subalternos, ao introduzir-se com seu ensaio de 1985 "Subaltern Studies: Deconstructing Historiography", como se fosse uma visita inesperada. Em contrapartida, o grupo Modernidade/Colonialidade se mostra mais aberto à academia feminista, e incorpora fragmentos dos escritos dos "feminismos de cor" dos Estados Unidos. Walter Mignolo empresta de Gloria Anzaldúa a ideia do "pensamento fronteiriço", mas ignora a magnitude e a complexidade da sua obra. Mignolo concebe o pensamento fronteiriço como uma epistemologia decolonial que se origina nas formas do saber do colonizado. Segundo o autor, o pensamento fronteiriço não apenas transcende o pensamento binário e dicotômico, como também consegue recuperar os saberes subjugados das garras do eurocentrismo (MIGNOLO, 2000).

Do mesmo modo, podem ser encontrados traços do pensamento feminista negro dos Estados Unidos nos debates do Grupo Modernidade/Colonialidade quando se referem à "constituição em conjunto" de raça e gênero e a articulação de múltiplos

\footnotetext{
${ }^{2}$ No lugar de argumentar que o colonialismo é irrelevante para o desenvolvimento do capitalismo como costuma ser feito, as obras do marxista peruano José Carlos Mariátegui (2009), por exemplo, já argumentava em 1920 que a questão da raça era central para o capitalismo, e a acumulação (do? Parece que falta algo aqui) capitalismo era incompreensível sem a devida atenção à produção de hierarquias raciais.
} 
sistemas de poder. Contudo, os teóricos decoloniais rapidamente se desvinculam da teoria de interseccionalidade do feminismo negro para substituí-la por outros conceitos como as heterarquias, do grego Kyriakos Kontopoulos, mais aptas para entender as múltiplas e heterogêneas hierarquias globais e a complexidade dos processos sociais dos distintos níveis estruturais (GROSFOGUEL, 2010, p. 71). Ainda que sejam incluídas algumas autoras feministas em suas antologias e elas sejam citadas em muitos dos seus trabalhos, a análise do gênero ainda ocupa um espaço inicial na teoria decolonial.

A recepção do conceito colonialidade de gênero de María Lugones é um caso paradigmático. Inspirada parcialmente nos escritos do Grupo Modernidade/ Colonialidade, Lugones atribui ao gênero o mesmo poder explicativo que Quijano atribui à raça dentro de sua conceitualização da colonialidade do poder, de forma que ele passa a ser compreendido igualmente como um construto social e colonial. Entretanto, apesar do reconhecimento público dedicado a Lugones, são poucos os teóricos decoloniais que incorporam o conceito colonialidade de gênero como fundamento central da teoria decolonial que eles constroem. Sem dúvida, a teoria feminista tem inspirado certos teóricos decoloniais em suas reflexões, mas não consegue ser reconhecida por completo como teoria "séria" por si só.

Algo similar acontece com o pensamento feminista anticolonial dentro da academia feminista dos Estados Unidos, anglo-americana, e das academias europeias, onde também é mantido à margem. Com a notável exceção da teoria feminista pós-colonial, que goza de grande prestígio, as demais vertentes do pensamento anticolonial feminista não recebem a mesma atenção. Já faz muito tempo que as teóricas feministas negras nos Estados Unidos observam que suas contribuições teóricas não são tratadas como "teoria" de fato dentro da academia feminista. Nikol Alexander Floyd (2012) declarou recentemente que a análise interseccional tem sofrido tal metamorfose empreendida pelas acadêmicas brancas hegemônicas que já não cumpre seu propósito principal, que é visibilizar a opressão das mulheres negras nos Estados Unidos. Vivian May (2014) afirma que o conceito de interseccionalidade tem sido reduzido a um enfoque monotemático de gênero por algumas pesquisadoras que não apenas recusam seu enfoque exclusivo em mulheres negras, mas que também questionam sua validade empírica. Outras teóricas feministas negras sentem que "dizem palavras ao vento" ou que estão sendo vítimas de um "contragolpe epistêmico" dentro da academia feminista dos Estados Unidos e Europa (MAY, 2014).

Esse contragolpe epistêmico é posto em evidência quando os trabalhos de feministas chicanas como Gloria Anzaldúa y Chela Sandoval são caricaturizados como simples políticas de identidade ou como modas acadêmicas facilmente superáveis por 
teorias pós-estruturais mais sofisticadas (ORTEGA, 2006). Ou, ainda, quando se fala dos estudos teóricos de feministas decoloniais como feminismos de "mulheres racializadas" (em oposição ao feminismo "propriamente dito"), eles são incorporados de forma segregada em programas de estudos étnicos, latinos, indígenas e afro-americanos, ou ignorados por completo. A política de citações da academia feminista hegemônica branca tolera a presença dos trabalhos das mulheres racializadas, mas distorce o conteúdo de suas ideias, falsifica suas genealogias, anula suas contribuições à teoria feminista e subjuga de forma veemente seus conhecimentos (ALEXANDER-FLOYD, 2012, p. 9), enquanto que os trabalhos escritos por feministas do "Terceiro Mundo" - isso implica dizer, fora dos Estados Unidos - nem sequer são considerados dignos de ser traduzidos, o que acarreta que eles passem a ser conhecidos já estando mediados ou reinterpretados por pesquisadoras do "Primeiro Mundo".

A partir de uma perspectiva feminista anticolonial, as teorias das mulheres racializadas estão sendo submetidas a um processo de recolonização, suas ideias centrais e preceitos são obrigados a desaparecer lentamente ou reaparecer "branqueados" e desprovidos de sua força crítica, considerando que um dos objetivos dos discursos feministas interseccional e decolonial nos Estados Unidos seja contrariar este contragolpe epistêmico por meio da recuperação do trabalho teórico de mulheres racializadas. $\mathrm{O}$ esforço está focado em criar uma lente multidimensional que sirva como base tanto para a teoria feminista decolonial quantopara as políticas de alianças entre mulheres racializadas (SANTACRUZ FEMINIST OF COLOR COLLECTIVE, 2014). Outros esforços incluem a recuperação de métodos e estratégias comuns das distintas teorias de feministas racializadas como resistência ao capitalismo global e o neocolonialismo (ROSHANRAVAN, 2014).

Quando a crítica ao colonialismo e ao neocolonialismo é considerada crucial para o projeto feminista anticolonial, torna-se evidente que os feminismos de cor dos Estados Unidos não mantêm parentesco com os feminismos anticoloniais, ainda que sejam parte importante desse projeto. Os feminismos de cor dos Estados Unidos contribuíram com conceitos fundamentais para o feminismo anticolonial, mas não são exaustivos: suas teorias não representam um gênero unificado e não compartilham um projeto intelectual ou político singular (ROSHANRAVAN, 2014), tampouco seus argumentos epistêmicos mais substantivos apresentam necessariamente um efeito decolonial. Portanto, é muito difícil identificar o que pode contar como feminismo anticolonial dentro e mais além do marco da academia das feministas racializadas. Vale lembrar as palavras das feministas indígenas dos Estados Unidos Eve Tuck e K. Wayne Yang (2012, p. 1, tradução da autora), que nos dizem que "as aspirações decoloniais de brancas, não-brancas, imigrantes e 
povos oprimidos e pós-coloniais muitas vezes reduzem a descolonização a uma metáfora de vagos desejos de liberdade e transformação social. Alguns discursos decoloniais incipientes, ainda pouco claros, correm o risco de restaurar normas coloniais, tornando-as mais fortes ao invés de enfraquecê-las". A descolonização não é uma metáfora para todas as críticas antirracistas, anticapitalistas nem tampouco das críticas ao eurocentrismo.

De fato, as teorias anticoloniais se definem por critérios vinculados a projetos políticos que conduzem à descolonização, mas as perguntas sobre quais critérios e quais projetos políticos são os que conduzem à descolonização, o que devemos entender por descolonização ou quais são as práticas que conseguem efetivamente desafiar o colonialismo e a colonialidade, são motivo de um intenso debate. Algumas sugerem que a meta principal da teoria feminista anticolonial é revelar e neutralizar os impulsos imperialistas e colonizadores que apresentam as teorias feministas hegemônicas. Umas pensam que a teoria anticolonial deve ter seu maior impacto no terreno da política, enquanto outras inserem sua análise na relação entre raça, gênero e colonização ou na análise da interseção entre raça, gênero e o Estado moderno. Como vemos, a forma como deve se situar a análise interseccional nos debates feministas anticoloniais ao redor das hierarquias criadas e sustentadas pela colonialidade do poder ainda está em disputa. Adiante, elaboro um marco teórico provisório para compreender mais a fundo os projetos teórico-políticos dos distintos feminismos anticoloniais. Trato de estabelecer primeiro a relação entre a teoria da interseccionalidade, o feminismo pós-colonial e decolonial com o projeto de descolonização, analisando seus vínculos com a corrente principal da teoria pós-colonial e decolonial, que está fortemente dominada por pesquisadores do gênero masculino.

\section{A INTERSECCIONALIDADE E A TEORIA ANTICOLONIAL}

Apesar de muitas pesquisadoras feministas considerarem a interseccionalidade um conceito revolucionário que redefiniu as abordagens da teoria, da política e das metodologias feministas (MCCALL, 2005; HANCOCK, 2011; CHO, CRENSHAW E MCCALL, 2013), esse conceito criado por pensadoras feministas negras dos Estados Unidos está recebendo fortes questionamentos já faz uma década. Seu valor epistêmico vem sendo questionado por feministas pós-estruturais que o consideram "meramente descritivo" (JORDAN-ZACHAERY, 2007 apud ALEXANDER-FLOYD, 2012, p. 5). Suas críticas têm sugerido que longe de contribuir com algo novo, a análise interseccional reproduz exatamente os velhos problemas das políticas de identidade, ao se concentrar de forma acentuada em categorias identitárias descontextualizadas e se ocupar excessivamente de um pequeno subconjunto de restrições estruturais, ou ao exagerar o racismo que Revista X, v. 16, n. 1, p. 290-318, 2021. 
existe dentro do feminismo. Outras críticas sugerem que a interseccionalidade mina a coerência filosófica e política do feminismo ao questionar a primazia da opressão de gênero, estigmatizar a categoria "mulher" ou divulgar narrativas que não podem abordar a complexidade do social (ZACK, 2005; GUNNARSON, apud MAY 2014, p. 102).

Algumas pesquisadoras têm tentado "corrigir" estas limitações da análise interseccional associadas ao seu foco exclusivo em mulheres racializadas, transformando-a em um método para o estudo de todas as mulheres, inclusive de todos os povos do mundo (GARRY, 2012). Muitas teóricas feministas negras dos Estados Unidos resistem a essa hiperinflação do conceito de interseccionalidade porque a análise de qualquer um dos múltiplos vetores do poder (por exemplo, o branqueamento, a análise de classe e a religião) tem o efeito de apagar as mulheres negras e de reconstituir as mulheres brancas como o centro de análise. Outras críticas do conceito têm tentado corrigir seus "problemas" mediante a recuperação das análises monocategoriais que investigam separadamente as dinâmicas de gênero ou de classe, ou através da escavação em complexos contextos sócio-históricos, dinâmicas locais e processos institucionais ou pela evasão de lógicas categoriais e assumindo abordagens polivalentes e multiníveis (GUNNARSON, 2014, p. 104). Alguns desses "remédios" não têm sido mais que a adoção superficial de uma abordagem que opera com uma lógica de adição a qual faz com que seja ininteligível a constituição dos sistemas de poder de gênero, raça, etnicidade, classe, sexualidade e nacionalidade, e destrói a premissa fundamental das análises interseccionais. Por isso, não é surpreendente que muitas teóricas feministas negras dos Estados Unidos percebam essas críticas displicentes e falsas interpretações da interseccionalidade como uma forma de violência epistêmica e de recolonização do conhecimento feminista negro.

Ao contrário do rechaço e da distorção que a interseccionalidade tem sofrido na academia branca dos Estados Unidos, os estudos feministas pós-coloniais e decoloniais tanto dentro como fora dos Estados Unidos - têm dado melhor acolhimento para essa teoria. O marco analítico interseccional vem sendo base para os feminismos do Terceiro Mundo que são críticos do colonialismo, feminismos que usualmente são conhecidos como "póscoloniais" (MOHANTY, RUSSO, TORRES, 1991). Ann McClintock, uma feminista póscolonial africana branca, nascida em Zimbabué e criada na África do Sul, argumentava no seu livro Imperial Leather (1995) que o colonialismo e o imperialismo não podem ser entendidos sem considerar a invenção da raça. Para McClintock, a análise interseccional reconhece que os sistemas de poder fundados no gênero, na raça, na classe e na sexualidade não são âmbitos sociais distintos e separados, mas parte de uma engrenagem perigosa que não está presente apenas dentro do colonialismo britânico, como também dentro das lutas 
anticoloniais. Como tem observado o Coletivo de Feministas de Cor de Santa Cruz (2014, p. 33), a teoria feminista anticolonial considera a análise interseccional muito além das críticas das práticas legais do Estado, lançando luz sobre as dinâmicas "glocais". 3

Nas últimas décadas, as linhas que separam o feminismo pós-colonial do feminismo de cor dos Estados Unidos têm sido distorcidas e matéria de disputa. Várias antologias agrupam textos clássicos do feminismo negro e chicano com escritos de feministas póscoloniais, publicando seus textos clássicos ao lado de escritos de feministas do Terceiro Mundo alinhadas no Grupo de Estudos Subalternos do Sudeste Asiático e com críticas ao orientalismo (LEWIS, MILLS, 2003). O agrupamento dessas abordagens distintas destaca a importância que a análise interseccional tem para o feminismo pós-colonial. No entanto, a homogeneização de diferentes tradições teóricas do "feminismo de cor" sob o amplo nome "feminismo pós-colonial" envolve também certos riscos que implicam sobretudo perder de vista o que é mais importante para o feminismo anticolonial. A teoria pós-colonial tem um programa teórico e político que não deve ser confundido com outras abordagens teóricas, porque existem importantes diferenças entre a teoria e prática feminista negra, chicana e a pós-colonial. Esses marcos teóricos se originam em distintas experiências e períodos coloniais, e desenvolvem distintos programas de pesquisa. Ao ocupar diferentes posicionamentos como sujeitos dentro dos distintos marcos nacionais, globais e das instituições acadêmicas, as posturas e apostas das autoras e ativistas que contribuem para a análise da interseccionalidade e da colonialidade são logicamente diversas. Precisamente porque surgem de diferentes tradições teóricas e partem de distintos projetos políticos, as teorias feministas negra, chicana e pós-colonial estão longe de ser uniformes. Ao invés de se supor que elas compartilham uma visão comum, é importante investigar se a crítica à colonialidade ou o projeto decolonial particular requer da análise interseções específicas.

Como vem sendo amplamente documentado em outros meios, as raízes intelectuais da análise interseccional se encontram nas pesquisas que as teóricas negras dos Estados Unidos têm realizado sobre a opressão da mulher negra, enfatizando a complexa interrelação entre raça, classe, gênero e desapropriação. O conceito foi rastreado nos discursos abolicionistas da ativista política Mary Stewart (1803-1880), no século XIX e, mais tarde, na obra de Anna Julia Cooper (1858-1964), cuja visão de mundo estava determinada pelo sistema de escravidão estabelecido e aprovado na legislação estadunidense, assim como na sua luta pela abolição desse sistema. Na segunda metade do século XX, o Coletivo

\footnotetext{
${ }^{3}$ Ou seja, a articulação entre o global e local que constroem gênero, raça, classe e sexualidade já não como categorias separadas, mas como sistemas de poder mutuamente constituintes que existem na e mediantes relações contraditórias e conflitivas.
} 
Combahee River criou a teoria da interseccionalidade da sexualidade, raça, gênero e classe. Kimberlé Crenshaw (1989) cunhou o termo "interseccionalidade" em seus estudos para se referir ao fracasso das cortes dos Estados Unidos que não reconhecem a discriminação baseada tanto em raça como em gênero. Patricia Hills Collins $(1990,1993)$ construiu a teoria sobre o ponto de vista do feminismo negro como uma ferramenta útil para lançar luz sobre a complexa opressão das mulheres negras.

Dentro do contexto dos Estados Unidos, a interseccionalidade serviu não só para tornar visível as dimensões da opressão da mulher negra que haviam sido ocultadas dentro da categoria unitária "mulher" da teoria feminista branca, senão que também desafiou os conceitos paradigmáticos de raça que eram utilizados dentro da teoria crítica de raça, dominada por homens negros. Ao enfatizar os vetores multidimensionais do poder que estruturam tanto a identidade vivida e a realidade social, o conceito de interseccionalidade jogou luz sobre os vínculos entre a localização epistêmica e a produção do conhecimento, além de oferecer estratégias analíticas capazes de associar o material com o discursivo e o estrutural. Além disso, ao mostrar a inadequação das formas binárias de pensamento e a futilidade dos esforços por hierarquizar as opressões, esse conceito reflete as lições que as teóricas feministas negras aprenderam a partir das suas experiências na escravidão, no desenraizamento, na desapropriação, na exploração econômica e reprodutiva, na segregação da era Jim Crow, na parceria no trabalho agrícola e doméstico, nos linchamentos, nas violações, nas manifestações racistas, na cidadania de segunda categoria e no racismo sistêmico dominante que permanece oculto dentro da igualdade formal.

Apesar de as criadoras do conceito interseccionalidade, sem saber, lançarem um projeto político que permanece atado ao Estado colonialista dos Estados Unidos, as historiadoras têm utilizado a análise interseccional para demonstrar como as opressões de gênero e sexual foram essenciais para o estabelecimento da escravidão e do sistema de plantação. Os economistas políticos provaram como o sistema de escravidão e de plantação continuam sendo a blueprint das relações econômicas e sociais dos Estados Unidos e a maneira como segue estruturada a segregação urbana e educacional, assim como o complexo industrial carcerário. Teóricas sociais têm descrito de que maneira os legados da escravidão e do apartheid legal se vincularam aos corpos negros de tal forma que até hoje determinam suas perspectivas de vida, suas relações sexuais, a formação de suas famílias, suas oportunidades econômicas, suas opções de moradia e emprego e a maneira como tudo isso forja laços fortes entre o passado colonial e o contexto póscolonial atual. Nesse contexto histórico e intelectual, a interseccionalidade (sem querer) 
promove demandas políticas de inclusão e igualdade de direitos, demandas para uma cidadania completa percebida como indispensável para uma vida livre.

Certos aspectos da política de interseccionalidade são assimilados dentro das políticas liberais de inclusão, o que enfraquece o seu potencial de descolonização. As noções liberais de "liberdade", "igualdade" e "justiça", tomadas da Declaração da Independência e da Constituição dos Estados Unidos, aparecem como as pré-condições do futuro das mulheres e homens negros estadunidenses, precisamente porque as "benesses da liberdade" foram negadas a eles por tanto tempo. Apesar disso, ao assumir a inclusão liberal como projeto político, a interseccionalidade sugere estratégias de ação e resultados desejáveis que se afastam das lutas anticoloniais fora dos Estados Unidos. Apesar da sua enorme influência às teorias pós-coloniais e decoloniais, os objetivos políticos das teóricas feministas negras se desviam com frequência das lutas anticoloniais de outras partes do mundo. Contudo, quando as feministas anticoloniais de fora dos Estados Unidos adotam a interseccionalidade como estratégia analítica, novos problemas são identificados e surgem possibilidades inesperadas dentro da complexidade das interseções de gênero, raça, classe e sexualidade que acontecem na condição colonial.

\section{OS DEBATES PÓS-COLONIAIS/DECOLONIAIS E A TEORIA FEMINISTA: O PÓS-COLONIALISMO}

Nos anos noventa, o tema do colonial foi retomado por teorias sociais, culturais e políticas. Após o declínio do marxismo e da ascensão do pós-modernismo e das teorias culturais pós-marxistas, a teoria pós-colonial passou a oferecer críticas inovadoras ao capitalismo, à Modernidade e ao colonialismo europeu. Inspirados em filósofos franceses como Michel Foucault e Jacques Derrida, os teóricos pós-coloniais mudaram os termos com os quais se pensavam o colonialismo, o capitalismo e o nacionalismo. Concentraramse na história do colonialismo britânico e seu declínio pós Segunda Guerra Mundial e tentaram produzir uma historiografia alternativa que desafiasse as teorias dominantes da análise histórica no Ocidente. Fizeram isso através da substituição do materialismo histórico por uma "história vista desde baixo" (CHIBBER, 2013), e da criação de um marco teórico novo para estudar a história colonial, que oferecia não apenas uma explicação para entender a subjetividade do capitalismo colonial da Índia, mas também o funcionamento do capitalismo em outras partes do mundo colonizado. Tendo em vista que o Grupo de Estudos Subalternos do Sudeste Asiático se voltou primordialmente para a colonização da Índia e de outras partes da Ásia, suas concepções sobre a relação entre o colonialismo e o capitalismo divergem dramaticamente das do Grupo Modernidade/ 
Colonialidade latino-americano, que parte de fases anteriores do colonialismo (espanhol, português e francês) e da descolonização. As diferenças essenciais entre suas concepções de colonialidade, modernidade e capitalismo serão a marca distintiva que separa não apenas essas duas correntes de pensamento - o pós-colonial do decolonial -, mas também serão as mesmas a diferenciar as suas contrapartes feministas.

Os "subalternos", considerados como o grupo nuclear da teoria pós-colonial, argumentam que o capitalismo assumiu uma forma radicalmente diferente no mundo colonial. Ao invés do papel "modernizante" que teve na Europa (ao transformar suas economias agrícolas em economias industriais e alienar os interesses da burguesia com os da classe operária para derrubar a aristocracia feudal), os efeitos do capitalismo no Sul da Ásia foram bifurcados. Segundo os subalternos, nem as forças progressivas nem o impulso universalizante do capitalismo se materializou de forma completa no subconsciente devido ao fato de as elites nacionalistas não terem conseguido transformar o "atraso" do campesinato no processo de descolonização (CHIBBER, 2013). Em termos gramscianos, os colonizadores britânicos e a classe capitalista nacionalista da Índia fracassaram ou não estiveram dispostos a generalizar seus interesses particulares com os da classe subalterna que exploravam. Apesar das mudanças superficiais na lei, o antigo regime e o sistema de castas se mantiveram de pé.

Diferente da experiência europeia, na qual a retórica burguesa dos direitos universais conseguiu recrutar a classe trabalhadora para o seu projeto político de democracia liberal, na Índia colonial a dominação capitalista envolveu um governo sem o consenso dos governados, isto é, sem hegemonia (CHIBBER, 2013, p. 13). Como consequência da longa história de dominação colonial britânica, as ideias liberais de "igualdade", "liberdade política", "secularismo" e "contratualismo" não se firmaram na Índia, o que alterou profundamente o contexto colonial. Ainda depois da Independência, as formas pré-capitalistas de exploração e dominação se mantiveram intactas. Esse desenvolvimento capitalista "anormal" dividiu a sociedade pós-colonial em dois campos de domínio político que obedecem a duas distintas lógicas contraditórias: enquanto a classe capitalista funciona de acordo com a busca racional do interesse individual, a subalterna fica preso em formas políticas pré-modernas, preocupada com assuntos religiosos, de casta, etnicidade e comunidade. Essa configuração singular de classe, segundo os subalternos, diferencia a modernidade colonial e o capitalismo na Índia, fazendo com que não haja semelhança alguma com o capitalismo e modernidade europeus. A ausência de hegemonia fez com que as elites nacionalistas da colônia construíssem uma forma de Estado nacional pós-colonial fictícia, baseada em uma legitimidade inautêntica (CHIBBER, 2013, p. 17), 
porque, como o modelo de desenvolvimento capitalista da Índia se diferenciava tanto do europeu, eles argumentaram que as categorias de análise ocidentais, e a teoria marxista em particular, eram inadequadas para compreender o capitalismo colonial do Oriente.

Influenciados pelas críticas pós-estruturalistas às teorias totalizantes, como, por exemplo, ao determinismo econômico de Marx, os Estudos Subalternos ofereceram uma narrativa alternativa ao capitalismo que evitava recorrer a "meta-relatos". Muito atentos ao poder do discurso, suas pesquisas se apoiaram cada vez mais em análises textuais da marginalidade e da subalternidade para assim conceber críticas ao colonialismo e ao capitalismo, complementares às discussões sobre exploração e dominação (CHIBBER, 2013, p.8). Ecoando a crítica à Modernidade pós-estruturalista, a crítica do eurocentrismo dos subalternos recusava as pretensões universalizantes de suas reivindicações, ao dar ênfase à diferença e ao local. Destacaram as especificidades do "Oriente" e utilizaram a análise cultural e histórica para teorizar o "subalterno" e levantar questões acerca da sua voz e ação. De acordo com Vivek Chibber (2013, p. 8), Gayatri Chakravorty Spivak, a teórica feminista pós-colonial mais reconhecida, foi a responsável indireta por essas características da crítica pós-colonial.

\section{FEMINISMO PÓS-COLONIAL}

Às vezes reconhecida como fundadora, e outras excluída do Grupo de Estudos Subalternos, Spivak se descreve como "uma feminista marxista desconstrutivista, prática e provocadora" (LEITCH et al., 2010, p. 2110). Colocando os subalternos, que ignoram o gênero e a sexualidade, como exemplo nos seus escritos, Spivak analisa o papel do gênero na divisão social do trabalho no capitalismo, critica o eurocentrismo na literatura ocidental, questiona os limites epistêmicos e políticos impostos pelo capitalismo neoliberal global e realiza críticas incisivas ao pensamento feminista liberal e radical ocidental. Spivak tem sido reconhecida por suas sofisticadas críticas às teorias pós-estruturais, pós-coloniais e feministas, assim como por suas análises do capitalismo colonial e da política pós-colonial.

Em seu ensaio "Pode o subalterno falar?" [(1985) 1988], Spivak estabeleceu os parâmetros da crítica feminista pós-colonial ao conceitualizar a violência epistêmica como intrínseca à produção do conhecimento ocidental. Spivak mostrou como a produção discursiva do subalterno, particularmente da "mulher pobre do Terceiro Mundo", teve o efeito de silenciar as mulheres do Sul Global por uma espécie de ventriloquismo, com o pretexto de dar voz aos oprimidos, ao subalterno permanentemente como ser passivo, irremediavelmente oprimido e essencialmente o outro dos sujeitos ocidentais. 
Em seu artigo intitulado "Sob os olhos do ocidente", Chandra Talpade Mohanty deixa cair todo o peso da crítica feminista pós-colonial sobre a academia feminista ocidental. Mohanty (1991, p. 56) demonstrou como as construções binárias que faziam uma distinção entre mulheres do Primeiro e do Terceiro Mundo homogeneizaram as mulheres de ambos os lados do binário com as consequências mais negativas recaindo sobre as do Terceiro Mundo, aquelas que são imaginadas como notáveis "ignorantes, pobres, sem educação, tradicionais, domesticadas, orientadas à família e vitimizadas", enquanto que as mulheres brancas foram construídas uniformemente como sendo "educadas, modernas, com controle sobre seus corpos e sua sexualidade e com a liberdade de tomar as suas próprias decisões". Esses discursos conflitantes não eram só eurocêntricos, como também, de acordo com Leela Gandhi (1998), fortaleciam uma imagem redentora da suposta plenitude ideológica e política do feminismo ocidental. Em uma paráfrase da denúncia feita por Spivak contra os meta-relatos dos homens brancos ocidentais que costumam representar seus atos colonialistas como "missões benevolentes de resgate", Mohanty repreende as feministas ocidentais as quais se imaginam como "mulheres brancas salvando mulheres de cor café dos homens também desta cor". Ainda que muitas autoras tenham criticado Mohanty por homogeneizar o feminismo ocidental, sua análise antecipou de muitas maneiras os discursos que circulariam depois do onze de setembro não apenas por líderes feministas dos Estados Unidos, mas também pelo governo, pelos meios ocidentais e por organizações de defesa dos direitos humanos (ABU-LUGHOD, 2013).

Mohanty também expandiu seu conceito das mulheres do Terceiro Mundo para além da cartografia estabelecida pelo Grupo de Estudos Subalternos. Na sua análise do capitalismo global, observou paralelismos entre os patriarcados heterogêneos capitalistas ocidentais e os não ocidentais que tinham a função de maximizar a exploração do trabalho das mulheres do "Terceiro Mundo" sem considerar se elas trabalhavam no Sul ou no Norte Global. Com o objetivo de maximizar suas ganâncias ao promover o consumo e prover os consumidores mais ricos com bens de consumo baratos, Mohanty sugeriu que as corporações multinacionais pioraram a precariedade da vida, ao reduzir os salários das mulheres e multiplicar os locais clandestinos de trabalho nas cidades globais tanto no Norte quanto no Sul e incrementar o desemprego no Norte Global. Ao criar um "contexto comum de lutas" e gerar "interesses comuns" baseados em exploração extrema, o capitalismo global formou a base para uma solidariedade transnacional entre mulheres do Terceiro Mundo.

Apesar de suas contribuições para a teoria feminista pós-colonial e para o feminismo transnacional, Mohanty não conseguiu resolver as relações de poder entre 
mulheres do Primeiro e do Terceiro Mundo que ela tão habilmente havia analisado em "Sob os olhos do Ocidente" (MENDOZA, 2002). Ainda que conceba as mulheres do Terceiro Mundo como sujeitos revolucionários, não diz nada sobre como os interesses comuns das mulheres do Terceiro Mundo que vivem na colônia ou nos centros metropolitanos podem ser transformados em lutas políticas coletivas contra a destrutividade do capitalismo global. Sua ênfase numa potencial solidariedade transnacional entre mulheres do Terceiro Mundo subestima a dificuldade que existe para mobilizar a união das mulheres do Primeiro e do Terceiro Mundos ou entre as mulheres brancas e as racializadas. Ao sugerir que os projetos de transformação surgem da experiência de opressão sistêmica, Mohanty faz ecoar a esquerda tradicional do Ocidente que defende que a revolução sempre começa com os mais marginalizados, e coloca assim toda a carga de responsabilidade na mulher subalterna. Ao focar nas opressões comuns que transcendem as fronteiras nacionais e a geopolítica do Norte/Sul, Mohanty se distancia também das posições do Grupo de Estudos Subalternos, que enxerga a ação política do subalterno motivada por uma série de demandas radicalmente contrapostas às do Ocidente. Ao invés de se ocupar da alteridade do subalterno, a orientação do feminismo transnacional de Mohanty a aproxima ainda mais dos marxistas convencionais que aclamam a solidariedade transnacional da classe trabalhadora como base da transformação social.

Em seus esforços de desmascarar o eurocentrismo e racismo dentro do feminismo ocidental, as teóricas feministas pós-coloniais puderam nos cativar com suas análises sobre a cultura popular, o cinema, os meios midiáticos, assim como com suas potentes críticas ao racismo e à racialização dos nacionalistas e do excepcionalismo estadunidense, dos sionistas e das elites nacionalistas do mundo pós-colonial (SHOHAT, STAM, 2006; FERNANDES, 2013). Seus estudos da interseção de gênero, raça, classe, sexualidade e nacionalidade nos proporcionaram conhecimentos profundos sobre a dinâmica que opera em distintos contextos coloniais (MCCLINTOCK, 1995; STOLER, 2002). Ao pesquisar os sistemas raciais construídos em certos contextos pós-coloniais, abriu-se a possibilidade para o diálogo com outras correntes que investigam o colonialismo espanhol e o português e não apenas o britânico, o francês ou o imperialismo yankee (STAM, SHOHAT, 2012). A erudição e a riqueza da pesquisa feminista pós-colonial são inegáveis.

No entanto, o feminismo pós-colonial tem as mesmas limitações associadas às principais correntes da teoria pós-colonial e pós-estrutural e seu desenvolvimento teórico tem sido acusado de determinismo cultural e historicismo, além de que o projeto político das feministas pós-coloniais também é difícil de compreender. Ainda que tenham colocado ênfase no papel do subalterno e no transnacionalismo das lutas contra o capitalismo global, 
e apesar de demonstrarem pouca esperança no potencial emancipatório do Ocidente, as teóricas feministas pós-coloniais também têm expressado preocupação acerca da capacidade do subalterno de transformar a sua condição colonial, particularmente na atual configuração do capitalismo neoliberal global. Como destacou recentemente Spivak (apud PAUDYAL, 2011) em uma conferência em Katmandu, Nepal, o subalterno tem sido "hegemonizado para aceitar sua miséria como algo normal". Se essa observação estiver correta, o que acontece com o projeto do intelectual pós-colonial de "treinar a imaginação" do subalterno para ajudá-lo a recuperar a bússola moral que o neoliberalismo o fez perder? A ideia de que o subalterno tem se resignado à sua miséria revela a distância social que separa a pesquisadora pós-colonial do subalterno. Ela destaca também o abandono das máximas de Foucault, que afirmam que o intelectual está irremediavelmente implicado nas redes de poder/conhecimento. Caso as teóricas feministas aceitem a premissa de Foucault de que não se pode criar um programa político representando o subalterno, ou se agarrem à noção de Gramsci do intelectual orgânico que pode falar pelo subalterno, a posição do subalterno e a do intelectual pós-colonial ficam claras diante da luta anticolonial. A mesma pergunta que foi colocada para o subalterno pode ser colocada para o crítico póscolonial: o intelectual ocupa uma posição privilegiada na luta pela descolonização ou está condenado ao silêncio?

\section{TEORIA DECOLONIAL}

Apesar de a teoria decolonial ser considerada por alguns como a encarnação mais recente da teoria anticolonial, essa abordagem apresenta uma visão histórica do colonialismo muito mais ampla do que a dos seus predecessores. Os teóricos decoloniais fundam suas análises no colonialismo espanhol e português que começou no século XVI e "terminou" no XIX. O pensamento decolonial atenta para a longa história do colonialismo espanhol e português que havia sido ignorada nos debates pós-coloniais, centrados exclusivamente no colonialismo britânico ou francês. Nas primeiras fases da expansão colonial europeia, foram fundadas as primeiras universidades coloniais em Santo Domingo, Lima e Cidade do México, já pelos anos de 1538 a 1551. Nesses centros de estudo ocorreram grandes debates sobre epistemologia e historiografia eurocêntrica e os intelectuais da elite crioula, dos mestiços e dos indígenas tentaram mostrar que o conhecimento europeu não podia reconhecer, muito menos compreender, as diferenças culturais e as formas de governo dos derrotados incas (MENDOZA, 2014). Mais de quatro séculos antes do surgimento do Grupo de Estudos Subalternos do Sul da Ásia, eruditos 
das universidades espanholas, tais como a Universidade de Salamanca e o Colégio São Gregório, já haviam questionado a justiça do império e a colonização.

Nos famosos debates de Valladolid (1550-1551), Bartolomé de las Casas e Ginés de Sepúlveda debateram acerca da humanidade do ameríndio e assim desafiaram os efeitos desumanizantes da colonização, além da retórica salvacionista dos missionários espanhóis (MENDOZA, 2006). Felipe Guamán Poma de Ayala, um nobre inca, escreveu as primeiras crônicas em defesa dos ameríndios e argumentou que os espanhóis não tinham direito de controlar os assuntos internos dos Andes. Em contrapartida, o inca Garsilaso de la Vega, também de origem nobre, tratou de recuperar as vozes e preservar a memória histórica dos ameríndios no exato momento em que eram sujeitos ao genocídio. Em um artigo muito sugestivo com o título "Sim, o subalterno pode falar: uma breve análise da Nova crônica e bom governo de Felipe Guamán Poma de Ayala e nos Comentários Reais do inca Garcilaso de la Vega", Lipi Biswas Sen, professor da Universidade de Nehru, na Índia, observa que esses relatos teóricos do subalterno do século XVI anteciparam os argumentos centrais do Grupo de Estudos Subalternos do Sudeste Asiático. De acordo com Guamán Poma de Ayala e Garcilaso de la Vega, os ameríndios resistiram ao pensamento binário dos europeus com a rejeição da ideia de "colonização" como sendo um processo "civilizatório". Os ameríndios inverteram a lógica da colonização e identificaram os europeus como os bárbaros que destruíam as civilizações estabelecidas há muito tempo pelos povos indígenas.

Diferente da teoria do subalterno dos sul-asiáticos que descrevem o subalterno com uma psicologia política incompatível com as formas de conhecimento do Ocidente, Guamán Poma de Ayala e Garsilaso de la Vega insistiram na ideia de que o subalterno havia dominado a língua espanhola e utilizava as ferramentas do "senhor", tais como o alfabeto escrito, para subverter os discursos coloniais dos europeus desde dentro (BISWAS SEN, 2009). De fato, a certeza de que o subalterno pode falar é uma das características que distingue a teoria decolonial, mas seus teóricos se diferem de muitas outras maneiras da teoria pós-colonial/subalterna e do feminismo pós-colonial. O Grupo Modernidade/Colonialidade insiste na ideia de que o capitalismo é concomitante ao colonialismo, que não é um sistema autônomo importado para as Américas. Com base em uma postura que contradiz aqueles que argumentam que o capitalismo existia na Europa antes da colonização, os teóricos decoloniais asseguram que o colonialismo é o que fez o capitalismo possível. Diferente daqueles que garantem que o capitalismo fracassou na Colônia devido às condições internas da sociedade indígena, o Grupo 
Modernidade/Colonialidade sustenta que o capitalismo requer das condições internas da colônia para a sua realização.

Os teóricos decoloniais veem o colonialismo como o lado obscuro da Modernidade, descartam a associação da Modernidade com os desenvolvimentos emancipatórios da Europa, tais como a Reforma, a Ilustração e a Revolução francesa, e sugerem no lugar disso relações causais muito mais complicadas entre colonialismo, a era da razão e as revoluções. Os pensadores decoloniais propõem que a escravidão, o trabalho forçado e a privação de direitos aos povos colonizados tornam as noções liberais de "liberdade", "igualdade" e "justiça" possíveis. A colônia é tanto a condição de possibilidade como o laboratório do Estado-nação ocidental e da figura do cidadão de direitos que está ligada aos proprietários do sexo masculino. Em outras palavras: a liberdade do europeu e do colonizador depende da privação de liberdade do colonizado. Como a liberdade de uns pressupõe a subordinação de outros, a descolonização é sempre um projeto não acabado. Apesar de o colonialismo ter deixado de existir em quase todas as partes do mundo, a colonialidade do poder ainda define as relações entre o Ocidente e o resto mundo.

Aníbal Quijano concebeu a colonialidade do poder como um processo de racialização intrínseco da colonização $(2010,2008)$. Começando com a conquista da América em 1492, os conquistadores europeus se autodenominaram "senhores do mundo", os líderes "naturais" dos povos "inferiores". Se tomamos a conquista como prova de sua superioridade, eles se deram ao direito de classificar povos inteiros de acordo com hierarquias fundadas em doutrinas religiosas, fisionomias, mitos sobre mandatos de pureza de sangue e de Divina Providência que os obrigava a difundir a palavra de Deus e os meios de salvação. Os conquistados foram condenados violentamente a viver na zona do não ser, desprovidos de humanidade, direitos e autodeterminação.

Segundo Quijano, a ideia de "raça" imposta na Colônia se originou nos debates que foram realizados durante a Inquisição espanhola e a Reconquista, e o princípio da "pureza de sangue" foi introduzido para diferenciar os "verdadeiros" cristãos dos judeus e mulçumanos convertidos. Com a invenção de noções enganosas que privilegiavam os católicos, a Igreja espanhola deu à Monarquia fundamentos para expulsar da Espanha os mouros e os judeus. Ainda que o princípio da pureza de sangue tenha sido evocado no início para legitimar uma hierarquia religiosa, com ele foram estabelecidas noções de superioridade biológica que tiveram repercussões culturais profundas, as quais resultaram particularmente úteis para a empreitada da conquista do "Novo Mundo", que veio depois. Importada para a América, a ideia de uma raça naturalmente superior e identificável por suas crenças e ações se converteu em uma ferramenta eficaz para diferenciar os 
colonizadores dos ameríndios e dos escravos trazidos da África. Uma vez marcados como seres inferiores, os povos conquistados e escravizados não só foram sujeitos aos decretos da monarquia católica espanhola, mas também a missões civilizatórias, a esforços "salvacionistas" e a exploração brutal da sexualidade e do trabalho.

A ideia de "raça", implícita nos debates acerca da "pureza de sangue", permitiu a construção de hierarquias que reestruturaram a organização social, assim como as instituições públicas e privadas do "Novo Mundo". Ao vincular noções de inferioridade biológica e cultural, a "raça" proporcionou um substrato versátil à colonialidade do poder que justificava um sistema social hierárquico capaz de dar aos colonizadores absoluto controle sobre os recursos humanos e materiais. Segundo Quijano, o conceito de raça reordenou todos os aspectos da sociedade indígena, incluindo as relações de gênero, trabalho, a autoridade coletiva, a subjetividade e a intersubjetividade. A raça designava quem seria escravo, forçado à servidão, ou trabalhador livre assalariado. Durante a Colônia, a raça determinou o status político e logo ditaria quem teria acesso a uma cidadania plena dentro do Estado-nação. Como fundamento do eurocentrismo, a raça definiu o que contava como história e conhecimento, e permitiu condenar os colonizados a viver como povos sem história, sem "direitos do homem" e sem direitos humanos. Dado que a produção do conhecimento europeu foi defendida como a do único conhecimento válido, as epistemologias indígenas foram reduzidas ao status de superstição primitiva ou foram destruídas. $\mathrm{O}$ eurocentrismo congelou as relações intersubjetivas entre europeus e não europeus em um marco temporal que posiciona ao europeu sempre como o mais avançado. Sem importar se a oposição binária enfrenta a civilização contra a barbárie, ou o trabalho assalariado contra a escravidão, o desenvolvimento contra o subdesenvolvimento, a superioridade do europeu permanece inquestionável (QUIJANO, 2008).

Com Aníbal Quijano como ponto de partida, os pensadores decoloniais têm desenvolvido uma série de conceitos que derivam da colonialidade do poder. Como Quijano, os teóricos decoloniais fazem uma diferença entre colonialidade e colonização. Diferente dos fatos históricos da colonização, nos quais uma nação impõe a sua soberania sobre outra, a colonialidade se refere a velhos padrões de poder que surgem no contexto do colonialismo e redefinem a cultura, o trabalho, as relações intersubjetivas, as aspirações do ser, o senso comum e a produção do conhecimento, de forma que a superioridade do europeu fica estabelecida. A colonialidade se mantém viva muito tempo depois de o colonialismo ter sido erradicado, e cala profundamente a consciência e as relações sociais da vida contemporânea. Edgardo Lander (2000) refletiu sobre a colonialidade do saber, e examinou as diversas práticas que silenciaram e erradicaram o conhecimento não 
ocidental e que continuam acontecendo na atualidade. Apresentando certa semelhança com a noção de violência epistêmica de Spivak, Lander estuda a exterminação física dos produtores de conhecimento não ocidental e as diversas tecnologias do genocídio intelectual. Fazendo um empréstimo de Walter Mignolo, Nelson Maldonado-Torres (2008) reinterpreta os conceitos centrais da fenomenologia existencialista como uma manifestação da colonialidade do ser, e reconstrói o modo com o qual a consciência do colonizador estrutura o cogito ocidental, de maneira que os descendentes dos europeus ainda rechaçam a humanidade plena dos povos não europeus.

\section{FEMINISMO DECOLONIAL}

O feminismo decolonial é atribuído muitas vezes ao trabalho das indígenas da América do Norte, às feministas chicanas, à teoria feminista anticolonial africana que foi publicada nos anos sessenta e setenta, mas o seu maior desenvolvimento aconteceu recentemente. O livro de Gloria Anzaldúa Borderlands/A fronteira (1987) costuma ser citado como texto fundador da teoria feminista decolonial. Seu conceito da consciência mestiça e o pensamento fronteiriço teorizou o caráter subversivo dos conhecimentos subjugados fraturando as línguas coloniais e as epistemologias, de maneira a mudar os termos do debate. Em 1999, Emma Pérez publicou The Decolonial Imaginary com o propósito de desafiar o imaginário colonial que persistia na historiografia nacionalista e patriarcal dos chicanos. As pesquisadoras indígenas norte-americanas, como Paula Gunn Allen (1986), e as teóricas africanas anticoloniais, como Oyèrónké Oyèwùmi (1997), também analisaram o impacto que o colonialismo teve sobre as mulheres e os discursos colonialistas do feminismo ocidental.

No presente, o feminismo decolonial é difundido em vários contextos culturais e nacionais. Catherine Walsh (2010) estudou a interculturalidade, saberes subjugados e decolonialidade no Equador. Seu conceito de interculturalidade é particularmente importante para a teoria decolonial porque se distancia de conceitos tais como multiculturalismo e pluriculturalismo promovidos pelo Banco Mundial para apoiar a sua agenda neoliberal. Para Walsh, a interculturalidade crítica não se refere à inclusão e nem a "se dar bem", se trata mais de um projeto político, ético e epistêmico da população indígena dos Andes que busca criar uma nova racionalidade e humanidade e assim reverter o eurocentrismo e a colonialidade do saber. Fora dos Estados Unidos, Madina Tolstanova, uma pesquisadora feminista natural de Kabardino-Balkaria, uma república da Federação Russa, agora radicada em Moscou, utiliza um marco decolonial para analisar o espaço e a subjetividade da era pós-soviética. Tlostanova pega emprestado de Mignolo o Revista X, v. 16, n. 1, p. 290-318, 2021. 
conceito da diferença imperial para estabelecer o lugar da União Soviética nas narrativas sobre impérios do Ocidente. Nelas, o império soviético não apenas se origina fora da Modernidade e ocupa a posição de um império subalterno, senão que a sua exterioridade à Modernidade e ao imaginário europeu permitem que a diferença imperial se transmute em uma diferença colonial. Isso determina os tipos de feminismo que emergem no espaço pós-soviético que, se bem definidos em termos de colonialidade, dificilmente podem ser entendidos como "feminismos de cor". Boa parte de seu trabalho sobre gênero e decolonialidade, entretanto, ainda não foi traduzida. Dentro da crítica cultural alemã, Freya Schiwy também utiliza uma lente decolonial para estudar gênero, subjetividade e colonialidade dentro dos estudos culturais dos Andes (SCHIWY, 2010).

A teoria decolonial vem apresentando um forte impacto na América Latina e no Caribe, ainda que algumas pesquisadoras feministas tenham questionado suas abordagens, sua origem geográfica e sua falta de perspectiva de gênero. Dentro dos círculos feministas, a teoria decolonial entrou em um diálogo com teóricas da interseccionalidade, feministas indígenas, afrolatinoamericanas e mestiças que desenvolveram suas próprias teorias à margem da oposição decolonial. Rita Segato (2001, 2011), uma antropóloga argentina radicada no Brasil, integra alguns elementos da teoria decolonial em seu trabalho, mas critica a noção de colonialidade de gênero, de Lugones, porque não acredita que as hierarquias de gênero fossem desconhecidas nas sociedades indígenas, como sugeriu Lugones. Silvia Rivera Cusicanqui, uma socióloga feminista de origem aymara e ativista na Bolívia - conhecida por seu trabalho na Oficina de história oral andina (THOA) -, denunciou a teoria decolonial como um discurso colonialista proveniente de universidades dos Estados Unidos, que não só não têm relação com as lutas locais dos povos indígenas da América Latina, mas também se apropria indevidamente e desconhece o trabalho sobre a colonização e descolonização que é desenvolvido na região há décadas (RIVERA CUSICANQUI, 2010, p.58). A teoria decolonial na América Latina também tem sido sujeitada a uma dupla crítica feminista. Uma delas, em particular a Quijano e Dussel, se centra na falta de atenção à dimensão de gênero ou em sua inadequada concepção de gênero (LUGONES, 2007; MENDOZA, 2010).

A teoria decolonial também tem ganhado adeptos na academia feminista dos Estados Unidos, ainda que não tenha apresentado o êxito instantâneo da teoria póscolonial nos anos noventa. Em duas de suas mais recentes publicações, "Heterosexualism and the Colonial Modern Gender System" (2007) e "Towards a Decolonial Feminism" (2010), Lugones introduziu a teoria decolonial para o público acadêmico feminista dos Estados Unidos, ao mesmo tempo em que expandiu os seus parâmetros ao incorporar 
a colonialidade de gênero e sexualidade. No seu ensaio de 2007, Lugones combina a interseccionalidade com a colonialidade do poder de Quijano para desenvolver sua própria concepção de colonialidade de gênero. Critica a ideia de "gênero" de Quijano por várias razões: permanece enclausurada no determinismo biológico; pressupõe o dimorfismo sexual onde não existia; naturaliza a heteronormatividade em culturas onde não se enxergava a homossexualidade nem como uma transgressão sexual ou social, e toma como certa uma distribuição do poder patriarcal em sociedades onde predominavam relações sociais mais igualitárias entre homens e mulheres. A partir da perspectiva de Lugones, a compreensão de gênero de Quijano é, na realidade, eurocêntrica. Logo, com base na pesquisa feminista de indígenas da América do Norte e do trabalho de Oyèwùmi sobre os iorubás, para corrigir a concepção equivocada de Quijano, Lugones argumenta que as sociedades indígenas não conheciam o "gênero" antes da intrusão europeia. O gênero não existia como um princípio ordenador do poder antes do processo de colonização. Ao invés de pensar que o "gênero" era uma característica perpétua da organização social, Lugones argumenta que ele deve ser entendido como um construto colonial, tal como a raça foi uma imposição europeia. No processo de colonização, tanto as mulheres quanto os homens da Colônia foram racializados e sexualizados quando o gênero passou a ser utilizado como uma ferramenta poderosa para destruir as relações sociais entre colonizados, causando profundas divisões e antagonismos entre eles. As construções europeias de gênero criaram hierarquias internas que romperam com a solidariedade que imperava entre homens e mulheres, destruindo seus laços prévios baseados na complementariedade e na reciprocidade. Ao invés de fomentar a colaboração harmônica, os colonizadores colocaram homens e mulheres em posição de antagonismo. Por meio de violência sexual, exploração e sistemas de concubinato, os colonizadores usaram o gênero para acabar com a autonomia de homens e mulheres indígenas e impor novas hierarquias que foram institucionalizadas com o colonialismo. Os corpos das mulheres se tornaram terrenos de negociações que os homens indígenas usaram para sua sobrevivência sob a nova ordem colonial. A única maneira de sobreviver culturalmente foi sacrificar de maneira perversa as mulheres à luxuria do conquistador. Lugones nomeia essa violência sexual sistêmica como o lado obscuro do sistema moderno/colonial de gênero.

Julieta Paredes (2008), uma ativista feminista aymara da Bolívia, critica o conceito de colonialidade de gênero, de Lugones, ao destacar que ele não permite ver a centralidade que o gênero tinha nas sociedades patriarcais indígenas antes da colonização europeia, e dá mais importância a outros processos coloniais antes da chegada dos europeus. No entanto, Lugones aprofunda sua análise da colonialidade de gênero no 
seu ensaio "Towards a Decolonial Feminism", no qual defende que o sistema de gênero imposto pelos europeus aos colonizados difere substancialmente do que foi imposto às mulheres europeias. Esse sistema multifacético de gênero subordinava as mulheres europeias, mas desumanizava os indígenas, escravos africanos e mulheres e homens mestiços. A partir da premissa central da colonialidade - a separação entre o humano e o não humano é concomitante à colonização -, Lugones sugere que a racialização dos não europeus como burros de carga teve profundas consequências para o desenvolvimento de complexos sistemas de gênero e sexo. As dicotomias hierárquicas que diferenciam o humano civilizado do primitivo natural, e a cultura da natureza, estruturaram não apenas as relações entre colonizadores e colonizados, mas também legitimaram a hierarquia que eleva os homens europeus por cima das mulheres europeias. O sentido do humano se viu bifurcado: como criaturas mais próximas da natureza, mais emocionais que racionais, presas à função animal da reprodução, as mulheres europeias ocuparam uma posição inferior à dos homens na grande cadeia do ser; apesar disso, conservaram seu status de humanas marcadas pela cultura.

O gênero civilizado abarcava uma hierarquia que subordinava as mulheres europeias aos homens europeus, mas deixava um enorme abismo aberto entre colonizadores e colonizados. Como selvagens, os colonizados manifestavam diferenças biológicas (sexo), mas careciam de um sistema de gênero. As relações igualitárias entre homens e mulheres indígenas eram, para os europeus, uma evidência de sua barbárie. Para Lugones, a hierarquia de gênero definiu o status de "civilizados" para as mulheres e homens europeus; a sua ausência marcou o não humano, a "racialidade", "naturalidade" dos não europeus, que eram seres sexuados, mas carentes de gênero. Vistos seja como animais hiper sexualizados ou como burros de carga, os povos indígenas e os escravos africanos foram percebidos como uma ameaça à ordem de gênero europeia. Como seres sub-humanos, os colonizados estavam aptos para a reprodução e sujeitos a formas cruéis de trabalho, exploração e massacre (LUGONES, 2012, p. 206). A colonialidade de gênero deixa claro que o gênero concede um status de civilidade unicamente para aqueles homens e mulheres que habitam o campo do humano; aqueles que carecem de gênero estão sujeitos à cruel exploração e ao genocídio claro e simples. Desta forma, a concepção da colonialidade de gênero de Lugones, como prática desumanizante que sobrevive à colonização, serve para compreender problemas contemporâneos como o feminicídio, o tráfico de mulheres e o aumento da violência contra as mulheres não europeias.

Na América Latina e no Caribe, a análise de Lugones da colonialidade de gênero teve uma recepção ambígua. Seu trabalho abriu um novo arquivo feminista do 
pensamento decolonial e produziu um grupo considerável de seguidoras. ${ }^{4}$ No entanto, seus argumentos específicos da colonialidade do gênero são controversos para algumas feministas hegemônicas, indígenas ou pesquisadoras que analisam a colonização e a descolonização a partir de outros marcos teóricos (MENDOZA, 2014). Algumas críticas questionam a validade empírica do trabalho etnográfico sobre o qual se baseia Lugones. A antropóloga argentina Rita Segato (2001), por exemplo, utiliza sua própria pesquisa dos iorubás na América Latina para questionar as teses de Oyèwùmi acerca da não existência de gênero entre eles. Apesar de reconhecer que o sistema de gênero iorubá é complexo e distinto do gênero europeu, e que a sua forma de patriarcado era de muitas maneiras menos intensa que a versão europeia, Segato nos apresenta com evidências suficientes que os dois demonstram a existência de uma forma de "gênero" que servia para estabelecer um status opressivo e hierárquico entre os iorubás. Segato sugere que os patriarcados de baixa intensidade se tornaram mais hierárquicos quando foram sujeitos à lógica de gênero da colonização, e que tiveram consequências graves para as mulheres indígenas. Na medida em que as esferas públicas e privadas foram separadas por gênero, as mulheres indígenas foram domesticadas e privatizadas fazendo com que elas perdessem o poder que possuíam dentro de suas comunidades. Ainda que os homens indígenas tenham conservado autoridade comunal, foram humilhados e castrados simbolicamente no cruel processo de colonização. Forçados a aceitar a lógica de gênero dos europeus, os homens indígenas retornaram às suas comunidades complementando seu antigo léxico de poder com novos códigos hierárquicos (SEGATO, 2011). Rivera Cusicanqui (2004) oferece críticas similares baseadas nas experiências das sociedades andinas. Apesar de que as relações de gênero indígenas eram mais igualitárias tanto na esfera pública quanto privada, o sistema de gênero andino estava organizado ao redor do casal heterossexual dentro de um sistema de complementariedade. Os sistemas de parentesco eram bilaterais, e davam tanto a homens quanto a mulheres direitos hereditários. Mulheres e homens alcançavam status social uma vez que formavam o casal e ambos ganhavam prestígio ao atingir a idade adulta. Rivera Cusicanqui observa que essas práticas não foram enfraquecidas ou totalmente destruídas durante a Colônia, senão foram os sistemas de governo republicanos, a modernização e o progresso os responsáveis por acabar com elas. O papel das mulheres na comunidade foi enfraquecido em uma época muito mais recente da que Lugones sugere em seu relato da colonialidade de gênero (CUSICANQUI, 2004). Segundo River Cusicanqui, as relações de gênero baseadas na complementariedade

\footnotetext{
${ }^{4}$ Vejam-se os trabalhos das integrantes do Grupo Latino-americano de Estudos, Formação e Ação Feminista (GLEFAS), disponíveis em: glefas.org.
} 
sobreviveram por muito mais tempo do que previamente se supunha, e foram destruídas no processo gradual de patriarcalização que acompanhou a modernização e a infiltração do Estado moderno nas comunidades andinas.

Na Bolívia, desde a eleição de Evo Morales, e no México, nas lutas revolucionárias dos zapatistas, os debates sobre a não existência do gênero antes da colonização foram muito importantes e de grande influência nas teorias da revolução e nas propostas feministas para políticas públicas, leis e imaginários políticos. Fora dessas lutas políticas, é muito provável que a questão sobre se o gênero é um construto colonial ou uma prática ancestral seja um falso dilema. O conceito da colonialidade de gênero de Lugones, a ideia de Segato de que os patriarcados pré-coloniais de baixa intensidade foram exacerbados pela colonização, e a teoria sobre a patriarcalização que acompanha a formação do Estadonação, de Rivera Cusicanqui, não devem ser interpretados como contraditórios. As três autoras estão de acordo sobre o fato de que a imposição do sistema de gênero europeu teve efeitos profundos sobre as relações entre homens e mulheres na Colônia, pois desencadeou forças letais genocidas contra as mulheres indígenas, as escravas africanas e as mestiças pobres. A conceitualização da colonialidade de gênero de Lugones é útil porque precisamente situa o gênero em relação com a razão genocida da colonialidade do poder. A lógica racializante que os europeus impuseram aos colonizados os despiu não apenas do seu status de humanos, mas também do status de seres com gênero. É o gênero que, no final das contas, provê humanidade e status social. Desprovidos de humanidade e de gênero, os não europeus ficaram para sempre à mercê da exploração e da aniquilação. A teoria de Lugones apresenta bastante semelhança com as teorias das indígenas da América do Norte, que já há muito tempo dizem que o Estado moderno/colonial opera com uma lógica de eliminação que permitiu o quase completo desaparecimento físico e simbólico dos ameríndios.

Sem importar se nos sustentamos em Lugones, nas teóricas feministas indígenas das Américas do Norte e do Sul ou em teóricas feministas latino-americanas, o pensamento decolonial oferece lições valiosas. A lógica racializante que foi introduzida na América em 1492 fez mais do que estruturar as relações entre colonizadores e colonizados: estabeleceu formas de pensar e modalidades de poder que continuam dando forma às relações sociais e políticas que permeiam todos os aspectos da vida no planeta. É imprescindível reconhecer a profunda influência que a racialização e a generificação tiveram para compreender o passado, para os esforços de transformar o presente e visualizar as estratégias de um futuro diferente. 


\section{REFERÊNCIAS}

ABU-LUGHOD, Lila. Do Muslim Women Need Saving? Cambridge: President and Fellows of Harvard College, 2013.

ALEXANDER-FLOYD, Nikol G. "Disappearing Acts: Reclaiming Intersectionality in the Social Sciences in a PostBlack Feminist Era." Feminist Formations 24(1), 2012, 1-24.

CÉSAIRE, Aimé. Discourse on Colonialism. Nova York: Monthly Review Press, 2000.

CHIBBER, Vivek. Postcolonial Theory and the Specter of Capital. Londres: Verso, 2013.

CHO, Sumi, CRENSHAW, Kimberlé, MCCALL, Leslie. 2013. "Intersectionality: Theorizing Power, Empowering Theory." Signs: Journal of Women in Culture and Society 38(4), 2013, p. 785-810.

CRENSHAW, Kimberlé. "Demarginalizing the Intersection of Race and Sex: A Black Feminist Critique of Antidiscrimination Doctrine, Feminist Theory and Antiracist Politics". University of Chicago Legal Forum 140, 1989, p. 139- 167.

DU BOIS, W. E. B. The Souls of Black Folks: Essays and Sketches. Cutchogue, Nova York: Buccaneer Books, 1976.

DUSSEL, Enrique. Philosophy of Liberation. Maryknoll, Nova York: Orbis Books, 1985.

FANON, Frantz. The Wretched of the Earth. Nova York: Grove Press, 2004.

FERNANDES, Leela. Transnational Feminism in the United States. Nova York: New York University Press, 2013.

GANDHI, Leela. Postcolonial Theory. NovaYork: Columbia University Press, 1998.

GARCILASO DE LA VEGA, Inca. “Comentarios Reales”. In Diferencia. Barcelona: Linkgua Ediciones, S. L, 2008.

GARRY, Ann. "Who Is included? Intersectionality, Metaphors, and the Multiplicity of Gender" In Out From the Shadows: Analytical Feminist Contributions to Traditional Philosophy, edited by Sharon L. Crasnow and Anita M. Superson, 493-530. Nova York: Oxford University Press, 2012.

GROSFOGUEL, Ramon. "The Epistemic Decolonial Turn: Beyond Political Economy Paradigms." In Globalization and the Decolonial Option, Walter D. Mignolo e Arturo Escobar (org.)., 65-77. Londres e Nova York: Routledge, 2010. 
GUAMÁN, Poma de Ayala, Felipe. Nueva Corónica y Buen Gobierno/Paris: Institut d'ethnologie, 1936.

GUNN ALLEN, Paula. The Sacred Hoop: Recovering the Feminine in American Indian Traditions. Boston: Beacon Press, 1986.

GUNNARSON, Lena. “A Defense of the category 'women."” In Feminist Theory 12(1), 2011, p. 23-27.

HANCOCK, Ange Marie. Beyond the Oppression Olympics: A Politics of Solidarity for the 21st Century. NovaYork: Palgrave Macmillan, 2011.

HILL COLLINS, Patricia. "Toward a New Vision: Race, Class, and Gender as Categories of Analysis and Connection." In Race, Gender and Class 1(1) (Outono): 25-45.

KONTOPOULOS, Kyriakos. The Logic of Social Structures. Cambridge: Cambridge University Press, 1993.

LANDER, Edgardo. La colonialidad del saber: eurocentrismo y ciencias sociales. Perspectivas Latinoamericanas. Buenos Aires: CLACSO, 2000.

LEITCH, Vincent B., CAIN E., WILLIAM, Finke Laurie A., JOHNSON, Barbara E. (eds.). The Norton Anthology of Theory and Criticism. Nova York; London: W.W. Norton, 2010.

LEWIS, Reina, MILLS, Sara. Feminist Postcolonial Theory. Nova York: Routledge, 2003.

LUGONES, Maria. "Heterosexualism and the Colonial Modern Gender System." Hypatia 22(1), 2007, p. 186-209.

LUGONES, Maria. “Towards a Descolonial Feminism.” Hypatia 25(4) (Fall), 2010, p. $742-759$.

MALDONADO-TORRES, Nelson. Against War: Views from the Underside of Modernity. Durham: Duke University Press Books, 2008.

MARIÁTEGUI, José Carlos. Siete ensayos de interpretación de la realidad peruana In Diferencia. Barcelona: Linkgua Ediciones, 2009.

MAY, Vivian M.'Speaking into the Void'? Intersectionality Critiques and Epistemic Backlash.” Hypatia 29(1), 2014, p. 94-112. 
MCCALL, Leslie. "The Complexity of Intersectionality." Signs: Journal of Women in Culture and Society 30(3), 2005, p. 1771-1800.

MCCLINTOCK, Anne. Imperial Leather. Nova York: Routledge, 1995.

MENDOZA, Breny. "Transnational Feminisms in Question." Feminist Theory 3(3), 2002, p. 295-314.

MENDOZA, Breny. "The Undemocratic Foundations of Democracy: An Enunciation from Postoccidental Latin America." Signs: Journal of Women in Culture and Society 31(4), 2006, p. 932-939.

MENDOZA, Breny. "La epistemologia del sur, la colonialidad de género y el feminismo latinoamericano." In Aproximaciones críticas a las prácticas teórico-políticas del feminismo latinoamericano, vol. 1, editado por Yuderkys Espinosa Miñoso, 19-36. Buenos Aires: Enla frontera, 2010.

MENDOZA, Breny. Ensayos de Crítica Feminista en Nuestra América. México D.F.: Editorial Herder, 2014.

MENDOZA, Breny. "La cuestión de la colonialidad de género" In Breny Mendoza Ensayos de Crítica Feminista en Nuestra América, 45-71. México D.F.: Editorial Herder, 2014.

MIGNOLO, Walter. The Darker Side of the Rennaissance: Literacy, Territoriality, and Colonization. Ann Arbor: University of Michigan Press, 1995.

MIGNOLO, Walter. Local Histories/Global Designs. Coloniality, Subaltern Knowledges, and Border Thinking. Princeton, NJ: Princeton University Press, 2000.

MOHANTY, Chandra T. "Under Western Eyes: Feminist Scholarship and Colonial Discourses." In Third World Women and the Politics of Feminism, 51-80. Bloomington: Indiana University Press, 1991.

MOHANTY, Chandra T., RUSSO, Ann; TORRES, Lourdes. Third World Women and the Politics of Feminism. Bloomington: Indiana University Press, 1991.

NKRUMAH, Kwame. Consciencism. Nova York: Monthly Review Press, 1964.

ORTEGA, Mariana. "Being Lovingly, Knowingly Ignorant: White Feminism and Women of Color" Hypatia 21(3), 2006, p. 56-74.

PAREDES, Julieta. Hilando fino desde el feminismo comunitario. La Paz, Bolívia: 
Comunidad Mujeres Creando Comunidad. CEDEC. Asociación Centro de Defensa de la Cultura, 2008.

PAUDYAL, Mahesh. 2011. Disponível em: <<http://www.ekantipur.com/thekathmandupost/2011/12/23/related_articles/the-dream-of-a-borderless-world/229620. html $>$.

QUIJANO, Anibal. "Coloniality of Power, Eurocentrism, and Social Classification." In Coloniality at Large, Marel Moraña et al. (org.)., 181-224. Durham, NC: Duke University Press, 2008.

QUIJANO, Anibal. "Coloniality and Modernity/Rationality." In Globalization and the Decolonial Option, Walter D. Mignolo e Arturo Escobar (org.)., 22-32. Londres e NovaYork: Routledge, 2010.

RIVERA CUSICANQUI, Silvia. 'La noción de "derecho" o las paradojas de la modernidad postcolonial: indígenas y mujeres en Bolivia.' Outubro. 1-9. Equador: Revista Aportes Andinos, 2004.

RIVERA CUSICANQUI, Silvia. Ch'ixinakax Utxiwa. Una reflexión sobre prácticas y discursos descolonizadores. Buenos Aires: Tinta Limón y Retazos, 2010.

ROSHANRAVAN, Shireen. "Motivating Coalition: Women of Color and Epistemic Disobedience." Hypatia 29(1), 2014, p. 41-58.

SANTA CRUZ FEMINIST OF COLOR COLLECTIVE. “"Building on Edge of Each Other's Battles': A Feminist of Color Multidimensional Lens.” Hypatia 29(1), 2014, p. $23-40$.

SCHIWY, Freya. "Decolonization and the Question of Subjectivity: Gender, Race, and Binary Thinking." In Globalization and the Decolonial Option, Walter D. Mignolo e Arturo Escobar (org.), 125-148. Londres e Nova York: Routledge, 2010.

SEGATO, Rita. "The Factor of Gender in the Yoruba Transnational Religious World." Brasilia. 2001. Disponível em: <http://www.scribd.com/doc/47347417/THE-FACTOROF-GENDER-IN-THE-YORUBA-TRANSNATIONALRELIGIOUS-WORLD $>>$. Acesso em: 27 mai. 2014.

SEGATO, Rita. "Género y colonialidad: en busca de claves delectura y de un vocabulario estratégico descolonial." In Feminismos y poscolonialidad. Descolonizando el feminismo desde y en América Latina, Karina Bidaseca e Vanesa Vazquez Laba (org.)., 17-48. Buenos Aires: Godot, 2011. 
SEN, Lipi Biswan. 'Sí, el subalterno puede hablar: un análisis breve de la "Nueva corónica y buen gobierno" de Felipe Guaman Poma de Ayala y los "Comentarios reales" del Inca Garcilaso de la Vega' Alicante: Biblioteca Virtual Miguel de Cervantes, 2009, p. 475-502.

SHOHAT, Ella, STAM, Robert. Flagging Patriotism. Nova York: Routledge, 2006.

SPIVAK, Gayatri Chakravorty. "Can the Subaltern Speak?" In Marxism and the Interpretation of Culture, Cary Nelson and Lawrence Grossber (org.)., 271-313. London: Macmillan, 1988.

STAM, Rober, SHOHAT, Ella. Race in Translation. Nova York: New York University Press, 2012.

STOLER, Ann Laura. Carnal Knowledge and Imperial Power: Race and the Intimate in Colonial Rule. Berkeley: University of California Press, 2002.

TUCK, Eve, YANG, K. Wayne. "Decolonization Is Not a Metaphor.” Decolonization: Indigeneity, Education \& Society 1(1), 2012, p. 1-40.

WALSH, Catherine. "Shifting the Geopolitics of Critical Knowledge: Decolonial Thought and Cultural Studies. 'Others' in the Andes." In Globalization and the Decolonial Option, Walter D. Mignolo e Arturo Escobar (org.). Londrese NovaYork: Routledge, 2010, p. 78-93.

ZACK, Naomi. Inclusive feminism: a third wave theory of women's commonality. Lanham, MD: Rowman \& Littlefield, 2005. 